\title{
Proposal of a new technique for bile duct reconstruction after iatrogenic injury. Study in dogs and review of the literature ${ }^{1}$
}

\author{
Reconstrução da via biliar após lesão iatrogênica, proposta de nova técnica. \\ Estudo em cães e revisão da literatura
}

\author{
Eduardo Crema², Eliane Anrain Trentini' ${ }^{3}$ Juan Carlos Llanos ${ }^{4}$ \\ 1. Research performed at Experimental Laboratory of Surgery Techniques, Department of Surgery, Federal University of Triângulo Mineiro (UFTM), \\ Minas Gerais, Brazil. \\ 2. PhD, Full Professor of Department of Digestive Surgery, UFTM, Minas Gerais, Brazil. \\ 3. Fellow Master degree, University of Campinas, São Paulo, Brazil. \\ 4. Fellow PhD degree, University State of São Paulo, Brazil.
}

\begin{abstract}
Purpose: Interposition of a jejunal tube between the common bile duct and duodenum. Methods: Five adult mongrel dogs of both sexes, weighing on average $22.3 \mathrm{~kg}$ (18 to $26.5 \mathrm{~kg}$ ), were used. Obstructive jaundice was induced by ligation of the distal common bile duct. After one week, a 2.5-cm long jejunal tube was fabricated from a segment of the loop removed $15 \mathrm{~cm}$ from the Treitz angle and interposed between the common bile duct and duodenum. Results: The animals presented good clinical evolution and no complications were observed. After 6 weeks, complete integration was noted between the bile duct mucosa, tube and duodenum and a significant reduction in total bilirubin and alkaline phosphatase was observed when compared to the values obtained one week after ligation of the common bile duct. Conclusion: The jejunal tube interposed between the dilated bile duct and duodenum showed good anatomic integration and reduced total bilirubin and alkaline phosphatase levels in the animals studied.
\end{abstract}

Key words: Biliary tract surgical procedures. Choledochostomy. Jaundice, obstructive. Dogs.

\section{RESUMO}

Objetivo: Interposição de um tubo de jejuno entre o colédoco e o duodeno. Métodos: Foram utilizados cinco cães adultos, sem raça definida, de ambos os sexos, com peso médio de 22,3 Kg (18 e 26,5 Kg). Após provocar icterícia obstrutiva pela ligadura do colédoco distal, após uma semana, praticou-se confecção do tubo de jejuno de 2,5 cm de extensão, que foi realizado com um segmento de alça retirado a $15 \mathrm{~cm}$ do ângulo de Treitz e a interposição do tubo entre o colédoco e o duodeno. Resultados: Os animais tiveram boa evolução clínica e não apresentaram complicações. Notouse total integração entre a mucosa da via biliar, do tubo e do duodeno e redução significativa dos valores da bilirrubina total e da fosfatase alcalina após seis semanas, quando comparado com os valores após uma semana de ligadura do colédoco. Conclusão: O tubo de jejuno interposto entre a via biliar dilatada e o duodeno, apresentou boa integração anatômica e reduziu os níveis de bilirrubina total e fosfatase alcalina dos animais estudados.

Descritores: Procedimentos cirúrgicos do trato biliar. Coledocostomia. Icterícia obstrutiva. Cães. 


\section{Introduction}

An increase in the diagnosis of asymptomatic gallstones has been observed over the last few years due to the improvement of diagnostic methods, particularly ultrasonography which is routinely performed on patients for various reasons and permits the detection of gallbladder stones. At the same time, laparoscopic cholecystectomy has become a widespread procedure and more patients, even when asymptomatic, wish to undergo surgery. As a result of the increase in the number of cholecystectomy procedures performed, mainly due to the learning curve of each surgeon, the incidence of bile duct injuries has also increased $1,2,3,4,6,7,8,910$. The incidence of bile duct injuries ranges from 0.1 to $0.3 \%$ even at referral centers. In Brazil, a national survey coordinated by Savassi Rocha et al. ${ }^{11}$, analyzing 91,232 laparoscopic cholecystectomy procedures, reported 167 bile duct injuries (0.018\%). Injuries to the hepatic bile duct or cystic duct stump, small lateral lesions or short strictures can be treated endoscopically. In these cases, endoscopic retrograde cholangiopancreatography is performed in combination with papillotomy and placement of a nasobiliary catheter or biliary prosthesis 7,12,13. Extensive lateral lesions, complete sectioning or ligation of the bile duct and long strictures require laparoscopic or laparotomic surgical treatment $14,15,16,17,18,19$. When the loss of bile substance is small, endto-end reconstruction can be performed as long as the suture can be placed without tension. Usually, a Kehr drain with a contralateral exit is inserted into the bile duct. Since in most cases the borders of the bile duct are separated or the distal portion cannot be identified, bile duct reconstruction is more frequently performed by choledochoduodenal or choledochojejunal Roux-en-Y diversion ${ }^{20}$. At present, good results have been reported for laparoscopic Roux-en-Y biliary-digestive anastomosis ${ }^{19,21}$. Although being the best therapeutic option for the treatment of proximal bile duct injuries, the disadvantage of a biliary-digestive anastomosis using an excluded jejunal loop is the deviation of bile from the duodenum and proximal jejunum. The absence of bile in these regions has metabolic repercussions and predisposes to the formation of peptic ulcers. In addition, this approach impairs or prevents diagnostic or therapeutic endoscopic access to the bile duct during the postoperative period. Interposition of a jejunal segment between the bile duct and duodenum for biliary reconstruction permits endoscopic access to the bile duct by upper digestive endoscopy. Biliary reconstruction by jejunal interposition has been performed for many years in humans in considerably large series and with good outcomes 22,23,24,25,26,27,28. However, the disproportion in the caliber between the bile duct and jejunum and the small jejunal segment employed may cause duodenaljejunal-biliary reflux. In addition, bile flow is impaired due to the transverse mucosal folding of the jejunum which may represent an obstacle to bile flow. In order to obtain a more anatomic and physiologic reconstruction of extensive bile duct lesions, we studied bile duct reconstruction in dogs by interposition of a tube consisting of a segment of the small bowel, similar to the procedure used by Monti for continent diversion of the neobladder ${ }^{29,30}$. The original procedure has been successfully used in humans for both cutaneous diversion of the neurogenic bladder and for ureter reconstruction. The same principle has also been applied to the fabrication of continent gastrostomies, permitting the intermittent insertion of a tube for the introduction of foods during gastrostomy without leakage when the tube is removed ${ }^{31}$. Monti observed that when sectioning the small bowel along its antimesenteric border and reconstructing it in the opposite direction, the small bowel "tube" does not present peristalsis. This tube then receives urine coming from the cranial direction and permits its passage without smooth muscle contraction, i.e., the "tube" permits unidirectional flow. In an attempt to restore the bile duct with a short segment of the small bowel with a caliber proportional to that of the hepatic bile duct and to minimize obstruction provoked by the circular folds of the jejunal segment, we propose in this study the interposition of a jejunal tube between the common bile duct and duodenum. The objective of the present study was to analyze whether the jejunal tube is able to restore bile transit from the previously ligated common bile duct to the duodenum and to reduce laboratory parameters of obstructive jaundice.

\section{Methods}

Five adult mongrel dogs of both sexes weighing on average $22.3 \mathrm{~kg}$ (18 to $26.5 \mathrm{~kg}$ ) were used. The surgical procedures were performed at the laboratory of the Discipline of Surgical Techniques and Experimental Surgery, Federal University of Triângulo Mineiro (UFTM). The research project was approved by the Ethics Committee on Animal Experimentation of UFTM. Before the surgical procedures, the animals were deprived of ration for $12 \mathrm{~h}$ and of water for $2 \mathrm{~h}$. Obstructive jaundice was induced in the animals by laparoscopic ligation of the common bile duct, and was confirmed before and 1 and 6 weeks after ligation by the measurement of alkaline phosphatase and total bilirubin.

\section{Anesthetic procedure}

For laparoscopic ligation of the common bile duct and biliary-digestive diversion, all animals received 0.1 $\mathrm{mg} / \mathrm{kg}$ acepromazine, intravenously, through the cephalic vein and $0.2 \mathrm{mg} / \mathrm{kg}$ morphine, intramuscularly, as preanesthetic medication. After $20 \mathrm{~min}$, anesthesia was 
induced by the intravenous administration of $5 \mathrm{mg} / \mathrm{kg}$ ketamine plus $0.5 \mathrm{mg} / \mathrm{kg}$ diazepam. The animals were positioned in supine decubitus on the trough of the surgical table and intubated with an orotracheal tube fitted with a balloon. Immediately after intubation, the probe was connected to an inhalation anesthesia apparatus in a semi-closed valvular circuit using a flow rate of the diluent of $1.0 \mathrm{l} / \mathrm{min}$ at $100 \%$ oxygen. Anesthesia was maintained with isofluorane administered through a universal vaporizer.

\section{Common bile duct ligation}

After anesthesia as described above, antisepsis was performed and sterile fields were placed. A $\mathrm{CO}_{2}$ pneumoperitoneum was established with a Verres needle introduced into the anterior wall of the abdomen $1 \mathrm{~cm}$ below the costal margin and $2 \mathrm{~cm}$ left from the midline. The pneumoperitoneum was maintained at about 12 $\mathrm{mmHg}$ with a digital inflator (20 liter/min). Four trocars, three measuring $5 \mathrm{~mm}$ and one measuring $10 \mathrm{~mm}$, were used. The bile duct was ligated close the upper border of the duodenum and was submitted to blunt dissection using Ethibond 2.0 suture.

\section{Biliary-digestive anastomosis}

Seven days after ligation, the animals were anesthetized and submitted to trichotomy, antisepsis and placement of sterile fields. A median laparotomy was performed from the xiphoid to $3 \mathrm{~cm}$ below the umbilical scar. Inspection of the abdominal cavity revealed dilatation of the hepatic bile duct upstream of the ligation and dilatation of the gallbladder. The $2.5-\mathrm{cm}$ long jejunal tube was fabricated using a segment of the loop removed $15 \mathrm{~cm}$ from the Treitz angle. The intestinal loop was sectioned proximally and distally after ligation of the vascular arcade, thus preserving irrigation of the 2.5cm long jejunal segment (pediculated flap). The jejunal segment was sectioned along the antimesenteric border in the longitudinal direction, with a vascularized rectangular flap measuring $4 \times 1.5 \mathrm{~cm}$ thus being obtained. The wall was closed throughout its extension by continuous cross-sectional total invaginating Schmiden type suture using 4.0 captocryl with a $2.5-\mathrm{cm}$ cylindrical needle. The tube was mounted using a No. 6 urethral probe on the mucosal surface of the flap, which facilitated suture and determined the lumen of the tube (Figure 1).

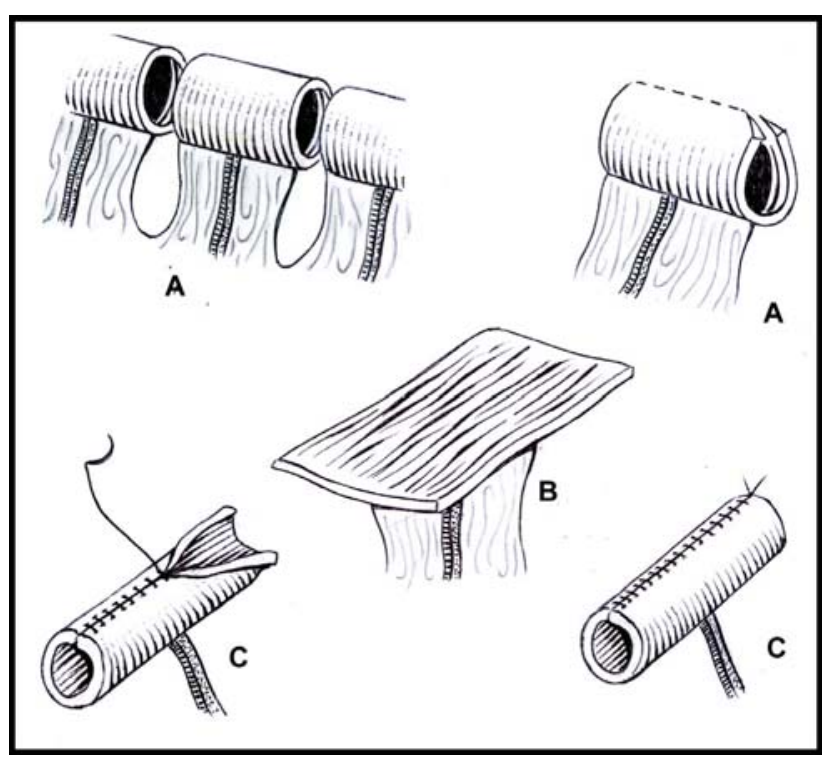

FIGURE 1 - Isolated intestinal segment at the jejunum (A) vascularized rectangular flap (B). The suture transversal the jejunum wall (C)

Interposition of the tube between the common bile duct and duodenum

After fabrication, the tube was moved to the supramesocolic region, with its vascular pedicle being intact and containing the urethral probe, through the opening of the transverse mesocolon on the right side of the middle colic vessels. The dilated common bile duct was dissected and sectioned throughout its circumference, with care taken not to devascularize it. End-to-end common bile duct-tube anastomosis was performed with total continuous sutures in the posterior hemicircumference using a single thread and with total separate simple sutures in the anterior hemicircumference, leaving knots outside the lumen. The previously placed urethral probe was kept inside the tube throughout the duration of the common bile duct-tube anastomosis, and its end was placed inside the dilated common bile duct. For tube-duodenum anastomosis, an opening measuring about $0.4 \mathrm{~cm}$ was introduced in the anterior wall of the duodenum, $2 \mathrm{~cm}$ distal from the pylorus. Before removal of the probe from the bile duct and tube, the absence of leakage from the common bile duct-tube anastomosis and suture line of the tube was tested by introducing $5 \mathrm{ml}$ physiological saline.

\section{Reconstruction of intestinal transit}

An entero-enteral anastomosis was performed after confirmation of good vascularization of the two ends of the loops. Anastomosis was performed by continuous total invaginating suture. After confirmation of 
hemostasis, laparorrhapy was performed by continuous suture of the aponeurosis and peritoneum using 0 prolene with a 3.5-cm cylindrical needle.

\section{Postoperative care}

The antibiotic Baytril (enrofloxacine) was administered only during anesthesia induction at the time of common bile duct ligation and induction and up to the sixth postoperative week for animals submitted to the surgeries for biliary-digestive anastomosis. The animals were sacrificed 7 weeks after ligation of the common bile duct and 6 weeks after biliary-digestive anastomosis. After anesthesia and laparotomy, the common bile duct was identified. The proximal bile duct, jejunal tube and a segment of the duodenum were

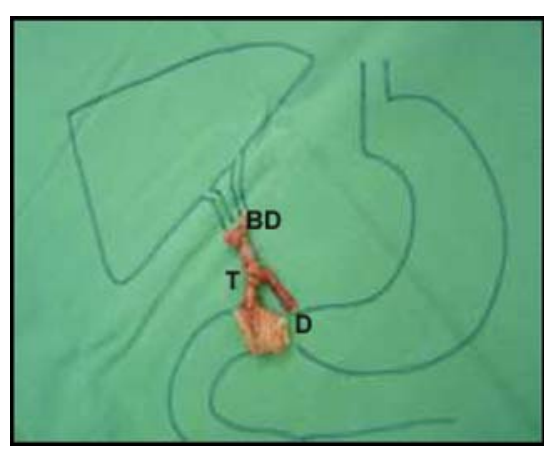

FIGURE 2 - The schem of interposition of the tube between the comom bile duct and duodenum.

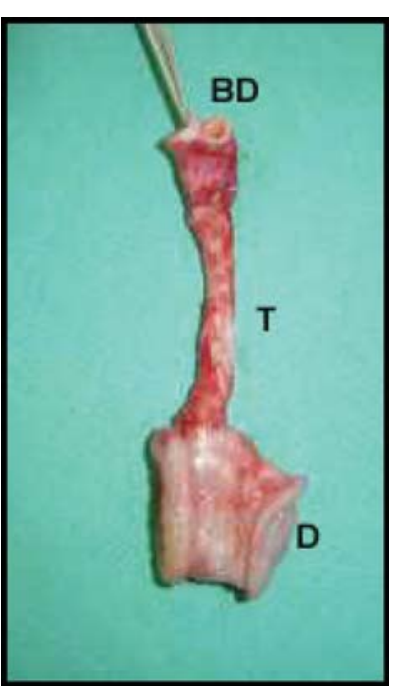

FIGURE 3 - The bile duct (BD), jejunal tube (T) and a segment of the duodenum (D)

dissected and removed en bloc (Figures 2 and 3). Statistical analysis

Descriptive and analytical statistics were used for comparison of the means according to a paired data design (Student t-test for paired data).

\section{Results}

All animals showed good clinical evolution until the end of the experiment. After one week, all five dogs presented an increase in total bilirubin $(4.24 \mathrm{mg} / \mathrm{dl})$ and alkaline phosphatase (3438 $\mathrm{mg} / \mathrm{dl}$ ) levels when compared to the mean values obtained before common bile duct ligation (0.12 and 57, respectively), with this difference being significant. After 6 weeks, the tubes were found to be viable and well positioned in the five animals studied (Figure 2) and analysis of the removed specimen showed complete integration between the bile duct mucosa, tube and duodenum (Figures 4 and 5). All animals presented a reduction in total bilirubin (0.12) and alkaline phosphatase (291) 6 weeks after the biliary-digestive anastomosis. A significant difference in total bilirubin (4.24) was observed at the time of biliary-digestive diversion $(\mathrm{P}=0.00068)$. There was also a significant reduction in alkaline phosphatase from 3438 after ligation to 291 at 6 weeks after interposition of the tube $(\mathrm{P}=0.0078)$.

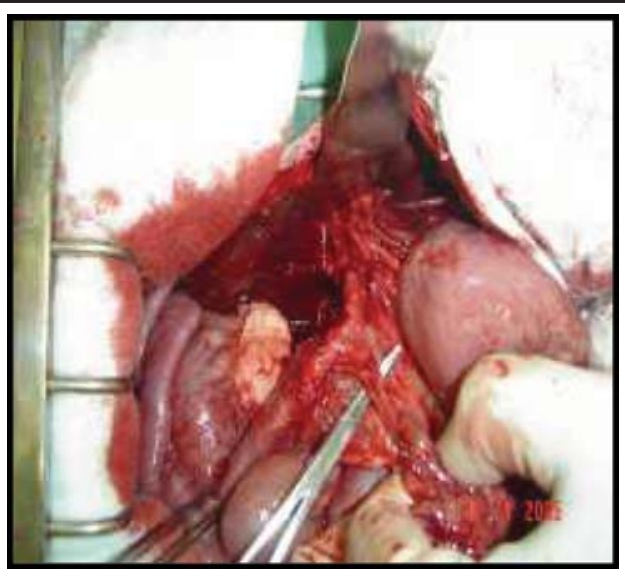

FIGURE 4 - Photo of well positioned of the jejunal tube (T) and vascular arcade (VA)

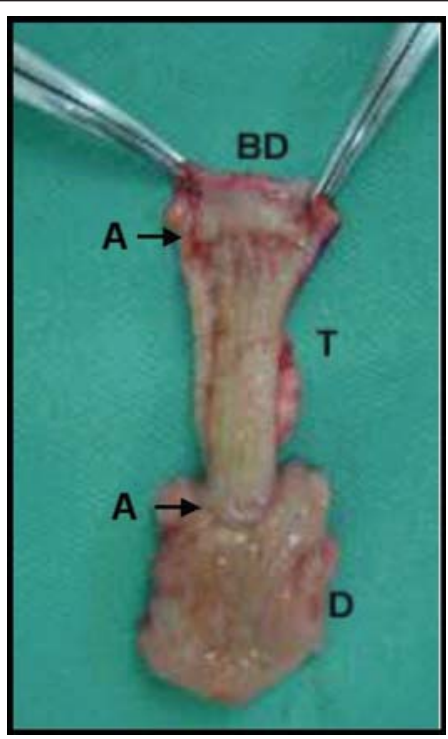

FIGURE 5 - It shows complete integration betweem the bile duct mucosal (BD), tube (T), and duodenum (D) anastomosis (A) 


\section{Discussion}

After the advent of laparoscopic surgery and routine ultrasound use in clinical practice, today a larger number of patients are submitted to cholecystectomy. As a consequence, a larger number of iatrogenic bile duct injuries have been reported, with the frequency of biliary injuries currently ranging from 0.1 to $0.3 \%$. A multicenter study conducted in Brazil analyzing 91,232 laparoscopic cholecystectomy procedures reported 167 (0.018\%) bile duct injuries. The authors concluded that the incidence of bile duct injury is similar for open and laparoscopic procedures and that these injuries increase surgical morbidity and mortality, as well as the time of hospitalization. Reconstruction of the bile duct after iatrogenic injuries usually requires a biliary-digestive anastomosis and frequently the use of an excluded jejunal loop because the distal bile duct cannot be identified. For choledochoduodenal anastomosis a sufficiently long segment of the common bile duct is necessary, which is usually not available during resurgery. In addition, most patients are young and this type of diversion increases the long-term chance of bile duct tumors due to chronic duodenal-biliary reflux. In the present project, anastomosis between the tube and normal bile duct was initially attempted and was possible without the use of a magnifying glass or microscope but the duration of surgery was long and the rate of anastomotic complications was high (18\%). After the decision to ligate the common bile duct to promote its dilatation, clipping of the distal common bile duct was initially tried, which caused sectioning of the bile duct and fistulae at the clipping level. Thus, the technique proposed by Kocher in 1997 using ligation with 2.0 suture was then employed. This method was efficient in promoting obstructive jaundice in all five animals studied, with total bilirubin and alkaline phosphatase levels being significantly higher one week after ligation. In an attempt to prevent deviation of bile from the duodenum and proximal jejunum, which is observed when reconstruction is performed with an excluded loop, several investigators have proposed the interposition of a jejunal segment between the hepatic bile duct and duodenum 22,23,24,25,26,27,28. In addition to the advantage of maintaining bile flow through the duodenum, it is important to guarantee the possibility of endoscopic access to the bile duct during the postoperative period, especially because of the potential risk of stenosis of these anastomoses and consequent recurrent cholangitis. The disadvantage of using the jejunum for interposition is the disproportion in caliber between the loop and the bile duct; in addition, the mucosal folding in the transverse direction functions as an obstacle to bile drainage, with the occurrence of stasis in the interposed jejunal segment. In the present experiment, a reduction in obstructive jaundice, indicating satisfactory bile flow through the tube, and a significant decrease in mean total bilirubin and alkaline phosphatase levels were observed 6 weeks after interposition of the jejunal tube. Another technical problem is the impossibility of using a duodenal-jejunal antireflux system because of the disproportion in caliber between these loops. In this respect, the technique proposed here using the jejunum in the shape of a tube permits adaptation of the tube-bile duct caliber and the mucosal folding of the tube becomes longitudinal, facilitating bile flow. In addition, it is possible to implant the tube in the duodenum as an antireflux mechanism. For example, Monti ${ }^{29,30}$ implanted the tube in the neobladder and used it as a replacement of the ureter, and Araújo ${ }^{31}$ employed the tube in gastrostomy. Implantation of the tube in the duodenum, as an antireflux mechanism, is part of another ongoing project in our laboratory, which has yielded partially satisfactory results.

\section{Conclusion}

The jejunal tube interposed between the dilated bile duct and duodenum showed good anatomic integration and reduced total bilirubin and alkaline phosphatase levels in the animals studied.

\section{References}

1. Archer SB, Brown DW, Smith CD, Branum GD, Hunter JG. Bile duct injury during laparoscopic cholecystectomy: results of a national survey. Ann Surg. 2001; 234(4): 549-59.

2. Sekido H, Matsuo K, Morioka D, Kunihiro O, Tanaka K, Endo I, Togo S, Shimada H. Surgical strategy for the management of biliary injury in laparoscopic cholecystectomy. Hepatogastroenterology. 2004; 51(56): 357-61.

3. Krahenbuhl L, Sclabas G, Wente MN, Schafer M, Schlumpf R, Buchler MW. Incidence, risk factors and prevention of biliary tract injuries during laparoscopic cholecystectomy in Switzerland. World J Surg. 2001; 25(10): 1325-30.

4. Ahrendt AS, Pitt HA. Surgical therapy of iatrogenic lesions of biliary tract. World J Surg. 2001 Oct; 25(10): 1360-5.

5. Zografakis JG, Jones BT, Ravichadram P, EvanchoChapman MM, Schmidt SP, Arends D, Funk KM, Gringas. Endoluminal reconstruction of the canine common biliary duct. Curr Surg. 2004; 60(4): 437-41.

6. Dubois F, Levard H, Berthelot G, Mouro J, Karayel M. Complications of celioscopic cholecystectomy in 2006. Ann Chir. 1994; 48(10): 899-904.

7. Rauws EA \& Gouma DJ. Endoscopic and surgical management of bile duct injury after laparoscopic cholecystectomy. Best Pract Res Clin Gastroenterol. 2004; 18(5): 829-46.

8. Jensen LS, Christiansen PM, Wara P., Jensen PM. Complications of cholecystectomy before and after introduction of laparoscopic surgery. Ugeskr Laeger. 2001; 163(6): 763-5. 
9. Anaise D. Complications of laparoscopic cholecystectomy. Internet $<$ http://www.danaise.com $>$. Acesso em 01/03/2006.

10. Schmidt SC, Langrehr JM, Schumacher G, Neuhaus P. Treatment of iatrogenic bile duct lesions from laparoscopic cholecystectomy. Rozhl Chir. 2005; 84(11): 567-72.

11. Savassi-Rocha PR, Almeida SR, Sanches MD, Andrade MA, Ferreira JT, Diniz MT, Rocha AL. Iatrogenic bile duct injuries. Surg Endosc. 2003; 17(9): 1356-61.

12. Davids PH, Ringers J, Rauws EA, de Wit LT, Huibregtse K, van der Heyde MN, Tytgat GN. Bile duct injury after laparoscopic cholecystectomy: the value of endoscopic retrograde cholangiopancreatography. Gut. 1993; 34(9): 1250-4.

13. Schwery S, Havelka J, Zaugg PY, Buhler H. The value of ERCP in the diagnosis and therapy of complications of laparoscopic cholecystectomy. Schweiz Med Wochenschr. 1994; 124(18): 771-5.

14. Savassi-Rocha PR, Ferreira JT, Diniz MT, Sanches SR. Laparoscopic cholecystectomy in Brazil: analysis of 33.563 cases. Int Surg. 1997; 82(2): 208-13.

15. Heise M, Schmidt SC, Adler A, Hintze RE, Langrehr JM, Neuhaus P. Management of bile duct injuries following laparoscopic cholecystectomy. Zentralbl Chir. 2003; 128(11): 944-51.

16. Robinson TN, Stiegmann GV, Durham JD, Johnson SI, Wachs ME, Serra AD, Kumpe DA. Management of major bile duct injury associated with laparoscopic cholecystectomy. Surg Endosc. 2001; 15(12): 1381-5.

17. Seeliger H, Furst A, Zulke C, Jauch KW. Surgical management of bile duct injuries following laparoscopic cholecystectomy: analysis and followup of 28 cases. Langenbecks Arch Surg. 2002; 387(78): 286-93.

18. Gazzaniga GM, Filauro M, Mori L. Surgical treatment of iatrogenic lesions of the proximal common bile duct. World J Surg. 2001; 25(10): 1254-9.

19. Crema E, Silva AA, Lenza RM, de Oliveira CB, Bridi VAU, Martins Junior A. Excluded-loop hepatojejunal anastomosis with use of laparoscopic in late management of iatrogenic ligature of the bile duct. Surg Laparosc End Percut Tech. 2002; 12(2): 110-4.
20. Rossi RL. Clínicas cirúrgicas da América do Norte: revisão das lesões do trato biliar. 4.ed. Rio de Janeiro: Interlivros; 1994.

21. O’Rourke RW, Lee NN, Cheg J, Swanstrom LL, Hansen PD. Laparoscopic biliary reconstruction. Am J Surg. 2004; 187(5): 621-4.

22. Moreno-Gonzalez E, Sanmartin JH, Azcoita MM, Serna AB. Reconstruction of the biliary tract using biliaryduodenal interposition of a defunctionalized jejunal limb. Surg Gynecol Obstet. 1980; 150(5): 678-82.

23. Chang TH, Chao HL. A new method for biliary tract reconstruction for primary bile duct stones. Arch Surg. 1986; 121(6): 720-2.

24. Oweida SW, Ricketts RR. Hepatico-jejunoduodenostomy reconstruction following excision of choledochal cysts in children. Am Surg. 1989; 55(1): 2-6.

25. Kremer B, Henne-Brubs D, Grimm H, Soehendra N. Bilio-duodenal jejunum interposition as a technical alternative to Roux-Y reconstruction following reconstruction of cancer of the fork of the hepatic duct. Chirurg. 1989; 60(9): 599-602.

26. Shamberger RC et al. Interposed jejunal segment with nipple valve to prevent reflex in biliary reconstruction. J Am Coll Surg. 1995; 180(1): 10-5.

27. Erhard J, Krause U, Hellinger A, Krischer V, Eigler EW. A new technique for reconstruction of the common bile duct after severe injury by laparoscopic cholecystectomy. Langenbecks Arch Chir. 1995; 380(6): 304-7.

28. Moellmann B, Ruhnke M, Kremer B. Cholangioduodenal interposition of an isolated jejunal segment after central resection. Hepatobil Pancr Dis Int. 2004; 3(2): 259-64.

29. Monti PR, Lara RC, Dutra MA, Carvalho JR. New techniques for construction of efferent conduits based on the mitrofanoff principle. Urology. 1997; 49(1): 112-5.

30. Monti PR, Carvalho JR, Arap S. The Monti procedure applications and complications. Urology. 2000; 55(5): 616-21.

31. Araújo LAO. Utilização do princípio de Monti para construção de uma gastrostomia continente [Tese Doutorado]. Recife: Federal University of Pernanbuco; 2004.

\section{Correspondence:}

Eduardo Crema

Rua Marcos Lombardi, 305

38050-170 Uberaba - MG Brazil

Phone: (55 34)3315-4500

Fax: (55 34)3318-5288

cremauftm@mednet.com.br
Conflict of interest: none Financial source: FAPEMIG

Received: January 24, 2007

Review: February 19, 2007

Accepted: March 16, 2007

How to cite this article:

Crema E, Trentini EA, Llanos JC. Proposal of a new technique for bile duct reconstruction after iatrogenic injury: study in dogs and review of the literature. Acta Cir Bras. [serial on the Internet] 2007 May-June;22(3). Available from URL: http://www.scielo.br/acb 